\title{
Porsuk Çayı'nda (Eskişehir) Sucul Makrofitler, Zooplankton ve Bentik Makroomurgasızların İncelenmesi
}

\author{
An Investigation on Aquatic Macrophytes, Zooplankton and Benthic \\ Macroinvertebrates in Porsuk River (Eskişehir)
}

\author{
Mine U. KIRKAĞAÇ ${ }^{1}$, Nilsun DEMİR ${ }^{1}$, Akasya TOPÇU ${ }^{1}$, Özden FAKIOĞLU ${ }^{1}$, \\ Özge ZENCİR ${ }^{2}$ \\ ${ }^{1}$ Ankara Üniversitesi Ziraat Fakültesi Su Ürünleri Mühendisliği Bölümü, Ankara \\ ${ }^{2}$ Erzincan Üniversitesi Kemah Meslek Yüksek Okulu Kemah, Erzincan
}

Özet: Bu araştırmada, Porsuk Çayı'nın Eskişehir İli içinden geçen bölümünde sucul makrofitler, zooplankton ve bentik makroomurgasızların Mayıs-Ekim 2007 ayları arasında incelenmesi amaçlanmıştır. Porsuk Çayi'nda Chlorophyta'dan Cladophora, Spirogyra ve Zygnema cinslerine ait türler ile Spermatophyta'dan Ceratophyllum demersum L., Lemna minor L., L. trisulca L., Myriophyllum spicatum L., Nasturtium officinale R. Brown, Potamogeton pectinatus L. ve Phragmites australis (Cavanilles) Trinius et Steudel türleri bulunmuştur. Sucul makrofit biyokütlesinin aylara göre $(p<0,05)$ ve istasyonlara göre $(p<0,01)$ değişimi istatistik olarak önemli bulunmuştur. Sucul makrofit biyokütlesi, Mayls ayından Ă̆ustos ayına kadar artış göstermiş, en yüksek değer Ă̆ustos ayında 2. istasyonda saptanmıştır. Sucul makrofitlerden baskın olan M. spicatum türünün biyokütlesi, içme su arıtım tesisi ve kum tutucunun bulunduğu istasyonlarda (1 ve 2) yüksek bulunurken, şehrin içinden geçen diğer üç istasyonda (3, 4 ve 5) sadece ipliksi alglere rastlanmıştır. Zooplankton bolluğunun istasyonlara $(p<0,05)$ ve aylara göre değişimi $(p<0,05)$ istatistik olarak önemli bulunmuştur. Rotifera grubundan 12, Cladocera'dan 3 tür ve Copepoda grubundan ise takım düzeyinde 2 zooplankton teşhis edilmiştir. Porsuk Çayı'nda 4. ve 5. istasyonlarda bentik makroomurgasızlardan Erpobdellidae, Tubificidae, Planorbidae ve Sphaeriidae familyasına ait üyeler teşhis edilmiştir. Bu araşstırmada Porsuk Çayı'nın durumu, zooplankton ve bentik makroomurgasız kompozisyonu açısından mesosaprobik-kirli olarak belirlenmiştir.

Anahtar kelimeler: Makroomurgası,, Sucul makrofit, Zooplankton, Porsuk Çayl.

\begin{abstract}
In this study, it was aimed to investigate aquatic macrophytes, zooplankton and bentic macroinvertebrates between May and September 2007 in Porsuk River where it is located in Eskisehir City. Aquatic macrophytes, from Chlorophyta filamentous species of Cladophora, Spirogyra and Zygnema genus, from Spermatophyta Ceratophyllum demersum L., Lemna minor L., L. trisulca L., Myriophyllum spicatum L., Nasturtium officinale R. Brown, Potamogeton pectinatus L. and Phragmites australis (Cavanilles) Trinius et Steudel were found. The variation of aquatic macrophyte biomass were found statistically significant according to months $(p<0.05)$ and stations $(p<0.01)$. The highest value of aquatic plant biomass increased from May to August and the highest value was determined at the $2^{\text {st }}$ station in August. The biomass of dominant aquatic macrophyte, M. spicatum was found to be high at drinking water treatment plant and sand trap stations (1 and 2) while only filamentous algae were determined at three stations (3, 4 and 5) in the city center. The variation of zooplankton abundance were found statistically significant according to stations $(p<0.05)$ and months $(p<0.05)$. Twelve species from Rotifera, three species from Cladocera and two zooplankter in order level from Copepoda were identified. Benthic macroinvertebrate members belong to Erpobdellidae, Tubificidae, Planorbidae and Sphaeriidae families were determined at $4^{\text {th }}$ and $5^{\text {th }}$ stations. In the study, the status of Porsuk River was determined as mesosaprobic-polluted with respect to zooplankton and benthic macroinvertebrate composition.
\end{abstract}

Key words: Macroinvertebrate, Aquatic macrophytes, Zooplankton, Porsuk River. 


\section{M.U.Kırkağaç vd.}

\section{Giriș}

İç sularda yaşamın en önemli elemanlarından biri olan sucul makrofitler, canlıların beslenmesi ve barınmasını sağlamakta, balıkların yumurtlama alanlarını oluşturmaktadır. Ayrıca ortamın sürdürülebilir kullanımı, yönetimi ve restorasyonu açısından büyük önem taşımaktadır.

Kirlenme indikatörü olarak zooplanktonlardan özellikle rotiferler kullanılmaktadır. Sladecek (1983), 620 rotifer türünün saprobik değerini tanımlamış, rotiferlerden Brachionus cinsinin ötrofik suları, Trichocerca cinsinin ise oligotrofik suları tercih ettiklerini bildirmiştir. Özellikle organik olarak kirlenmiş sularda, flagellata ve ciliata gruplarına ait organizmaların artış gösterdiği belirtilmiştir (Foissner ve Berger, 1996).

Sularda kirlenme indikatörü olarak makroomurgasızların kullanımı, kimyasal analizlerde gözden kaçırılabilecek kısa süreli değişimler açısından bir erken uyarı mekanizması sağlamaktadır. Bentik makroomurgasızlardan Tubificidae ve Chironomidae larvaları gibi bazı organizmalar kirliliğe karşı yüksek tolerans gösterirken, Ephemoreptera ve Tricoptera gibi bazı gruplar oldukça hassastır (Hawkes, 1979; Metcalfe-Smith, 1994).

Ülkemizde akarsulara ilişkin kalite ölçümleri, nüfus ve sanayi üretiminin dolayısıyla kirlenmenin daha yoğun olduğu Batı bölgesindeki havzalarda yoğunlaşmıştır (Türkmen ve Türkmen, 1999; Kazanc1 ve Dügel, 2000; Kayar ve Çelik, 2003; Küçük, 2007). Bu havzalardan bir tanesi de Sakarya Havzası olup, Porsuk Çayı, Sakarya Nehri'nin kirliliğini oluşturan bileşenlerden biridir. Porsuk Çayı'nda ve havzasında kirliliğe yönelik çeşitli araştırmalar yürütülmüştür (Çiçek ve Koparal, 2001; Ocak ve ark., 2002). Yüce ve ark. (2004), 2001 yılında Porsuk Çayı, yüzey ve yer altı sularını incelemişler; azot, fosfor ile ağır metal derişimlerinin artış gösterdiğini ve çayın sulama suyu olarak kullanımının uygun olmadığını bildirmişlerdir. Bingöl ve ark. (2007), Yukarı Porsuk Çayı epilitik diatomlarının son yıllardaki değişimlerini çayda kirliliğin arttığı şeklinde yorumlamışlardır. Muhammetoğlu ve ark. (2005), Porsuk Çayı ve Porsuk Baraj Gölü'nde su kalitesini belirlemek amacıyla çeşitli modeller kullanmışlardır. Baraj girişinde yüksek azot ve fosfor derişiminden dolayı Porsuk Çayı'nın besin seviyesinin hiperötrofik olduğu belirtilmiştir. Porsuk Çayı'nda kirletici kaynakların yüzey suyu ile taban suyuna etkisi araştırılmış ve 1998 yılında uygulamaya başlanan kanalizasyon sisteminden sonra taban suyunun kalitesindeki değişimler belirlenmiş, atık suların çaya doğrudan boşaltılmasının durdurulması gerekliliği ortaya konmuştur (Yüce ve ark., 2006).

Porsuk Çayı'nın Eskişehir İli içinden geçen bölümünde su kalitesinin bozulmasından kaynaklanan koku sorununa yönelik olarak yapılan eşzamanlı bir araştırmada, fitoplankton kompozisyonu, klorofil $a$, su sıcaklığı, çözünmüş oksijen, $\mathrm{pH}$, Secchi derinliği, besin tuzları gibi bazı su kalite parametreleri incelenmiştir (Demir ve ark., 2011).

Bu araştırmada, Porsuk Çayı'nın Baraj Gölü’nden sonraki Eskişehir İli şehir merkezi içinden geçen bölümünde su kalitesinin indikatörü olarak; sucul makrofit, zooplankton ile bentik makroomurgasızların bollukları, dağılımları ve kompozisyonunun incelenmesi amaçlanmıştır.

\section{Materyal ve Yöntem}

\subsection{Araştırma Yeri}

Sakarya Nehri'nin en önemli kolu olan Porsuk Çayı Kütahya il sınırları içinden kaynağını almakta ve Eskişehir kent merkezinden de geçerek yaklaşık $460 \mathrm{~km}$ sonra Polatlı yakınlarında Sakarya Nehri'ne karışmaktadır (Ocak ve ark., 2002). Porsuk Çayı Batı Anadolu Platosu'nda deniz seviyesinden 1170 m yükseklikteki Tokul Köyü civarından doğar ve deniz seviyesinden yaklaşı 600 m yükseklikte Sakarya Nehri'ne ulaşır. Çayın su toplama havzası $11325 \mathrm{~km}^{2}$, y1llık ortalama su debisi ise yaklaşık 300 milyon m³'tür (Anonim, 1998; Bingöl ve ark., 2007). Porsuk Çayı'nın başlıca 
kullanım amaçları ise evsel ve endüstriyel su temini, tarımsal sulama ve balıkçılıktır. Ancak evsel ve endüstriyel atık sular için alıcı ortam olan çayda kirlenmenin başlamasıyla balıkçılık önemini yitirmiştir (Anonim, 1998; Çiçek ve Koparal, 2001).

Eskişehir Belediyesi tarafından Porsuk Çayı'nın Eskişehir il merkezi içerisinden geçen bölümünde doğal afet zararlarını azaltmak üzere su seviyesinin kontrolüne yönelik bir inşaat projesi yürütülmüş̧ür (Büyükerşen ve Efelerli, 2005). Bu projeye göre, Porsuk Akarsu Kanalının yaklaşık 8 km uzunluğunda bir bölümü geliştirilmiş ve düzenlenmiştir. Kanalda su seviyesini yükselten, birbirine bağlayan dört adet su seviye kontrol yapısı inşa edilmiştir.

\subsection{Arazi Çalışması ve Laboratuar Analizleri}

Araştırma süresince inşaat çalışmaları devam ettiği için su seviyesinde önemli değişimler olmuş ve kanaldan su boşaltıldığı için bazı istasyonlardan örnekler alınamamıştır. Araştırma, Porsuk Çayı'nda Porsuk Barajı sonrasında (Aşağı Porsuk) belirlenen 5 istasyonda yürütülmüştür (Şekil 1); 1. istasyon Porsuk Barajı sonrası İçme Suyu Arıtım Tesisi'nde, 2. istasyon kum tutucu yapı sonrası, 3. istasyon Taşköprü-Tülomsaj (1. seviye kontrol yapısı sonrası), 4. istasyon Köprübaşı (2. seviye kontrol yapıs1 sonrası), 5. istasyon Salhane (3. seviye kontrol yapısı sonrası) olarak seçilmiştir.

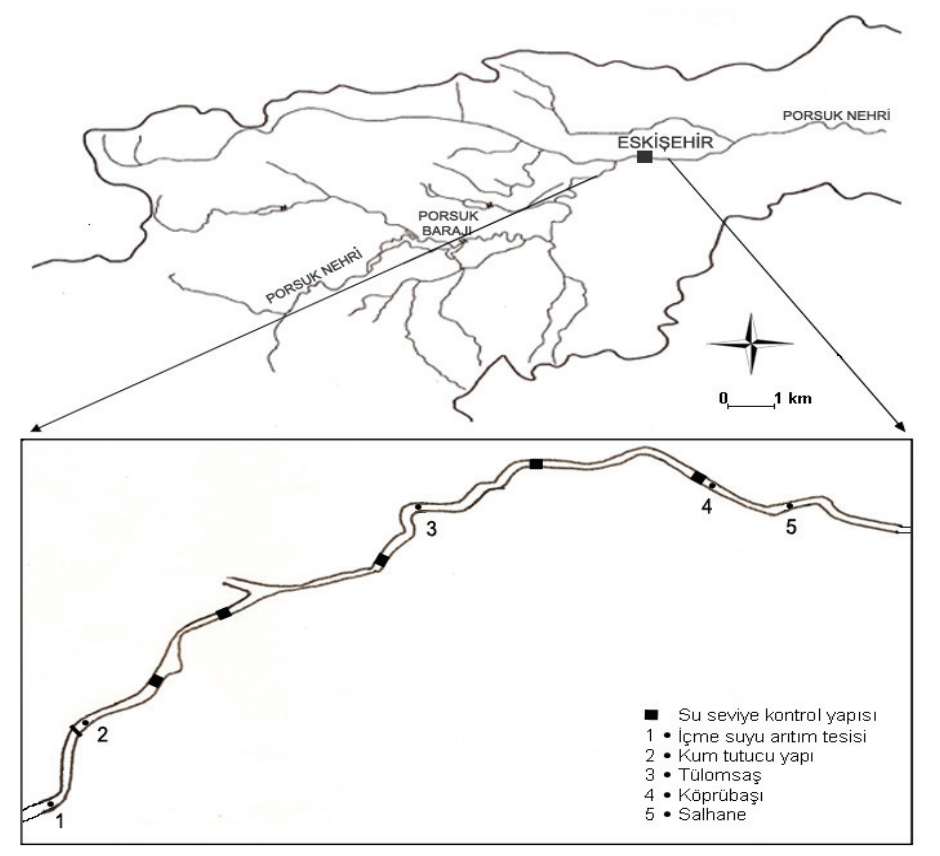

Şekil 1. Porsuk Çayı'nda örnek alınan istasyonlar ve su seviye kontrol yapıları.

Porsuk Çayı'nda sucul makrofit örnekleri, her istasyonda bir burgunun sapı etrafinda tam olarak döndürülmesiyle 3 tekrarlı olarak alınmıştır. Kısa makrofitlerin alınmasında Ekman kepçesi kullanılmıştır. Alınan örnekler, bitkilere yapışan artıklar, algler ve dipten gelen çamur tabakasının temizlenmesi için yıkanmıştır. Yıkanan örnekler, fazla suyun alınması için kurulanmış ve polietilen torbalarda muhafaza edilerek etiketlenmiştir (Westlake, 1986). Bitkiler laboratuara getirildikten sonra lup, stereomikroskop ve binoküler mikroskop kullanılarak teşhisleri yapılmıştır (Lund ve ark., 1958; Prescott, 1973; Casper ve Krausch, 1980, 1981). Sucul bitki biyokütlesi birim alanda yaş ve kuru ağırlık bazında belirlenmiştir. Makrofitler türlerine göre ayrıldıktan sonra hassas terazi ile yaş ağırlıkları tartılmış ve $\mathrm{m}^{2}$ 'deki yaş ağırlıkları belirlenmiştir. Yaş ağırlığı ölçülen bitkilerden alınan alt örnekler darası alınmış kaplara konarak $105^{\circ} \mathrm{C}$ 'da 24 saatte kurutulmuş ve desikatörde soğutulduktan sonra kuru ağırlıkları belirlenmiştir (Westlake, 1986; Wetzel ve Likens, 1991). 
Zooplanktonun incelenmesinde, alınan su örnekleri \% 4'lük formaldehit çözeltisiyle fikse edilmiş, 1000 ml'lik ölçü silindirlerinde çöktürülmüş ve sayım hücrelerine alınarak invert mikroskopta sayılmıştır (Edmonson ve Winberg, 1971). Plankton kepçesi ile süzülen örneklerdeki zooplankton türleri binoküler mikroskop yardımıyla teşhis edilmiştir (Edmondson, 1959; Ruttner-Kolisko, 1974; Smirnov, 1974; Koste, 1978). Bentik örnekler $15 \times 15 \mathrm{~cm}$ boyutlarındaki Ekman çamur alma aleti ile iki tekrarlı olarak alınmıştır. Alınan çamur örnekleri göz açıklığı 210 ve $3360 \mu \mathrm{m}$ arasında değişen bir seri elekten geçirilerek süzülmüştür. Toplanan organizmalar \% 4'lük formaldehitte saklanmıştır. Bentik faunanın teşhisi stereomikroskop yardımıyla yapılmıştır (Edmondson, 1959; Macan, 1975).

\section{Bulgular}

Araştırma periyodunca Porsuk Çayı'nda örnek alınan istasyonlarda yoğun olarak bulunan sucul makrofit ve alglerin istasyonlara ve zamana bağlı değişimleri incelenmiş ve su içinde Chlorophyta'dan ipliksi Cladophora, Spirogyra ve Zygnema cinslerine ait türler ile Spermatophyta'dan Ceratophyllum demersum, Lemna minor, L. trisulca, Myriophyllum spicatum, Nasturtium officinale ve Potamogeton pectinatus türlerinin bulunduğu belirlenmiştir (Çizelge 1). Toplam sucul makrofit biyokütlesinin aylara $(\mathrm{p}<0,05)$ ve istasyonlara göre $(\mathrm{p}<0,01)$ değişimi istatistik olarak önemli bulunmuştur. Sucul makrofit biyokütlesi, Mayıs 2007'den Ağustos 2007'ye kadar artış göstermiş, en yüksek değer 1. ve 2. istasyonlarda saptanmış ve Ağustos 2007'de 2. istasyonda $331 \pm 116 \mathrm{~g} / \mathrm{m}^{2}$ 'ye ulaşmıştır. Phragmites australis, 1. ve 2. istasyonlarda su kıyısında kemer teşkil etmektedir. Şehir içinde bulunan 3., 4. ve 5. istasyonlarda çayın kıyı kesiminde sucul bitki tespit edilmemiştir. Özellikle 2. istasyonun, yani kum tutucunun bulunduğu noktanın su bitkilerince çok zengin olduğu belirlenmiştir. 1. istasyonda, içme suyu arıtım tesisi su alma yapısının yakınında su içi bitkilerin bulunduğu, 2. istasyonda su dibinin su içi bitkiler ve makroalglerle kaplandığı tespit edilmiştir. Su bitkilerinin 3., 4. ve 5. istasyonlardaki kompozisyonu aylara bağlı değişim göstermiştir. Islah çalışmaları nedeniyle su seviyesinin düzensiz oluşu, özellikle 5. istasyonda bulanıklığın fazla oluşu, su içi bitkilerinin bulunuşunu önleyebilecek faktörler olarak saptanmıştır

Çizelge 1. Porsuk Çayı'nda örnek alınan istasyonlarda araştırma süresince teşhis edilen sucul makrofit, alg, zooplankton ve bentik makroomurgasızlar.

\begin{tabular}{|l|l|}
\hline ALG VE MAKROFITLER & Rotifera \\
\hline Chlorophyta & Polyarthra dolicoptera (Idelson) \\
Cladophora sp. & Hexarthra sp. \\
Zygnema sp. & Lecane cornuta (O.F.M.) \\
Spirogyra sp. & Lecane luna (O.F.M.) \\
Spermatophyta & Mytilina mucronata \\
Ceratophyllum demersum L. & Cladocera \\
Lemna minor L. & Bosmina longirostris (O.F.M.) \\
Lemna trisulca L. & Ceriodaphnia quadrangula (O.F.M.) \\
Myriophyllum spicatum L. & Daphnia sp. \\
Nasturtium officinale R. Brown & Copepoda \\
Phragmites australis (Cavanilles) Trinius et Steudel & Cyclopoid copepod \\
Potamogeton pectinatus L. & Calanoid copepod \\
\hline ZOOPLANKTON & BENTIK FAUNA \\
\hline Rotifera & Gastropoda \\
Branchionus urceolaris (O.F.M.) & Planorbis sp. \\
Branchionus calcyflorus Pallas & Physa sp. \\
Branchionus angularis Gosse & Sphaerium sp. \\
Cephalodella gibba (Ehr.) & Hirudinea \\
Cephalodella catellina (O.F.M.) & Erpobdellidae \\
Colurella sp. & Oligochaeta \\
Euchlanis dilatata (Ehr.) & Tubifex sp. \\
\hline
\end{tabular}


İçme suyu arıtım tesisi su alma yapısında (1. istasyonda), Cladophora ile birlikte bazı ipliksi algler bulunmakla birlikte Myriophyllum spicatum türünün yayılım gösterdiği ve yoğun olarak bulunduğu belirlenmiştir. Bu türün biyokütlesi Ağustos 2007'de en yükssek değerine $\left(257 \pm 99 \mathrm{~g} / \mathrm{m}^{2}\right)$ ulaşmış, Eylül 2007'de su alma yatağı civarında derinleştirme ve çamur temizleme işlemi yapıldığından oldukça düşük bulunmuş, ancak Ekim 2007'de 2. istasyonda tekrar $\left(136 \pm 27 \mathrm{~g} / \mathrm{m}^{2}\right)$ artmıştır (Çizelge 2). 2. istasyon, kum tutucu yapının önünde suyun derinleştiği ve su akımının yavaşladığı bir konumda bulunmaktadır. Bu nokta, su bitkilerinin çeşitliliği açısından en zengin örnekleme alanıdır. Su içi bitkileri yanı sıra, su kıyısında da çeşitli sucul bitkiler bulunmaktadır. Ekim 2007 dişında 3., 4. ve 5. istasyonlarda sadece Cladophora ve diğer ipliksi algler bulunmuştur.

Çizelge 2. Porsuk Çayı'nda örnek alınan istasyonlarda belirlenen sucul makrofit biyokütlesinin aylık değişimi (Ortalama \pm Standart hata, kuru ağırlık bazında $\mathrm{g} / \mathrm{m}^{2}$ ).

\begin{tabular}{|c|c|c|c|c|c|c|c|c|c|}
\hline Ay & İst. & $\begin{array}{l}\text { Zygnema } \\
\text { Spirogyra }\end{array}$ & Cladophora & $\begin{array}{c}C . \\
\text { demersum }\end{array}$ & L. minor & $\begin{array}{c}M . \\
\text { spicatum }\end{array}$ & N. officinale & $\begin{array}{c}P . \\
\text { pectinatus }\end{array}$ & $\begin{array}{c}\text { Toplam } \\
\text { Biyokütle }\end{array}$ \\
\hline \multirow{5}{*}{ 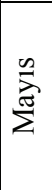 } & 1 & - & - & - & $7,6 \pm 1,20$ & $5,98 \pm 0,93$ & - & $2,43 \pm 0,30$ & $16,01 \pm 2,42$ \\
\hline & 2 & + & $9,0 \pm 1,50$ & - & $2,29 \pm 0,60$ & $12,83 \pm 4,72$ & + & - & $24,12 \pm 7,0$ \\
\hline & 3 & - & - & - & - & - & - & - & - \\
\hline & 4 & - & - & - & - & - & - & - & - \\
\hline & 5 & - & - & - & + & + & - & + & - \\
\hline \multirow{5}{*}{ 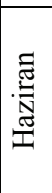 } & 1 & $3,97 \pm 1,43$ & $5,19 \pm 1,72$ & - & + & $29,75 \pm 9,80$ & - & + & $38,91 \pm 12,95$ \\
\hline & 2 & $10,50 \pm 0,75$ & $4,86 \pm 2,09$ & - & + & $55,84 \pm 12,4$ & - & - & $71,12 \pm 15,24$ \\
\hline & 3 & $7,12 \pm 1,11$ & - & - & - & - & - & - & $7,12 \pm 1,11$ \\
\hline & 4 & - & - & - & - & - & - & - & - \\
\hline & 5 & - & - & - & - & - & - & - & - \\
\hline \multirow{5}{*}{ 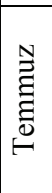 } & 1 & - & $10,48 \pm 3,55$ & - & $3,87 \pm 0,90$ & $161,38 \pm 43,20$ & - & $0,90 \pm 0,20$ & $176,63 \pm 47,85$ \\
\hline & 2 & $2,62 \pm 0,32$ & $8,73 \pm 2,08$ & - & $6,97 \pm 2,05$ & $78,17 \pm 21,70$ & - & - & $96,49 \pm 21,7$ \\
\hline & 3 & $11,65 \pm 3,71$ & - & - & - & - & - & - & $11,65 \pm 3,71$ \\
\hline & 4 & $8,16 \pm 2,16$ & - & - & - & - & - & - & $8,16 \pm 2,16$ \\
\hline & 5 & $10,2 \pm 4,8$ & - & - & - & - & - & - & $10,2 \pm 4,8$ \\
\hline \multirow{5}{*}{ 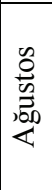 } & 1 & - & $31,79 \pm 7,22$ & - & $7,73 \pm 1,95$ & $83,27 \pm 36,01$ & - & $3,76 \pm 1,13$ & $126,55 \pm 46,31$ \\
\hline & 2 & $2,76 \pm 0,91$ & $37,09 \pm 5,93$ & $9,45 \pm 2,30$ & $9,90 \pm 2,93$ & $256,89 \pm 98,80$ & $14,04 \pm 4,50$ & $1,10 \pm 0,40$ & $331,23 \pm 115,77$ \\
\hline & 3 & $7,65 \pm 2,13$ & $28,20 \pm 6,15$ & - & - & - & - & - & $35,85 \pm 8,28$ \\
\hline & 4 & $5,16 \pm 1,08$ & $23,77 \pm 4,11$ & - & - & - & - & - & $28,93 \pm 5,19$ \\
\hline & 5 & $4,50 \pm 1,10$ & - & - & - & - & - & - & $4,50 \pm 1,10$ \\
\hline \multirow{5}{*}{ 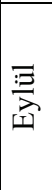 } & 1 & - & $34,50 \pm 12,70$ & - & $1,30 \pm 0,03$ & $5,12 \pm 2,70$ & - & $2,15 \pm 0,80$ & $43,07 \pm 16,23$ \\
\hline & 2 & $3,15 \pm 1,30$ & $56,12 \pm 23,93$ & - & $4,82 \pm 2,05$ & $70,12 \pm 13,67$ & - & - & $134,21 \pm 40,95$ \\
\hline & 3 & $2,87 \pm 1,80$ & $5,60 \pm 2,0$ & - & - & - & - & - & $8,47 \pm 3,8$ \\
\hline & 4 & $*$ & $*$ & * & $*$ & $*$ & $*$ & $*$ & $*$ \\
\hline & 5 & $1,39 \pm 0,15$ & $1,87 \pm 0,70$ & - & - & - & - & - & $3,26 \pm 0,85$ \\
\hline \multirow{5}{*}{ 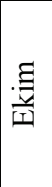 } & 1 & - & - & - & $4,54 \pm 1,55$ & $33,66 \pm 12,30$ & - & $1,56 \pm 0,70$ & $39,76 \pm 14,55$ \\
\hline & 2 & $2,20 \pm 0,70$ & $74,17 \pm 24,80$ & - & $5,0 \pm 2,32$ & $136,42 \pm 27,10$ & - & - & $217,79 \pm 54,92$ \\
\hline & 3 & - & $8,14 \pm 2,76$ & - & - & $35,05 \pm 12,54$ & - & - & $43,19 \pm 15,3$ \\
\hline & 4 & $3,26 \pm 1,31$ & - & - & - & - & - & - & $3,26 \pm 1,31$ \\
\hline & 5 & $5,09 \pm 1,93$ & - & - & $1,19 \pm 0,57$ & - & - & - & $6,29 \pm 2,5$ \\
\hline
\end{tabular}

(*)Islah çalışmaları nedeniyle örnek alınamadı (+) Bitkinin nadir olarak dağılım gösterdiği gözlendi.

(-) Makrofit kaydedilmedi.

Porsuk Çayı'nda Rotiferlerden Branchionus, Cephalodella, Colurella, Euchlanis, Hexarthra, Lecane, Mytilina ve Polyarthra cinslerine ait 12 tür, Cladocera'dan ise Bosmina, Ceriodaphnia ve Daphnia cinslerine ait 3 tür teşhis edilmiştir. Copepoda takım düzeyinde incelenmiştir (Çizelge 1). Araştırmada Haziran 2007'de 4. istasyonda, Temmuz 2007'de 2., 3. ve 5. istasyonlarda, Ağustos 2007'de 4. ve 5. istasyonda, Ekim 2007'de ise 5. istasyonda zooplanktona rastlanmamıştır (Şekil 2). Zooplankton bolluğunun en yüksek değeri Mayıs 2007'de 1. istasyonda $62 \pm 15$ adet/l olarak 
belirlenmiştir. Zooplankton bolluğunun istasyonlara $(p<0,05)$ ve aylara göre değişimi $(p<0,05)$ önemli bulunmuştur.

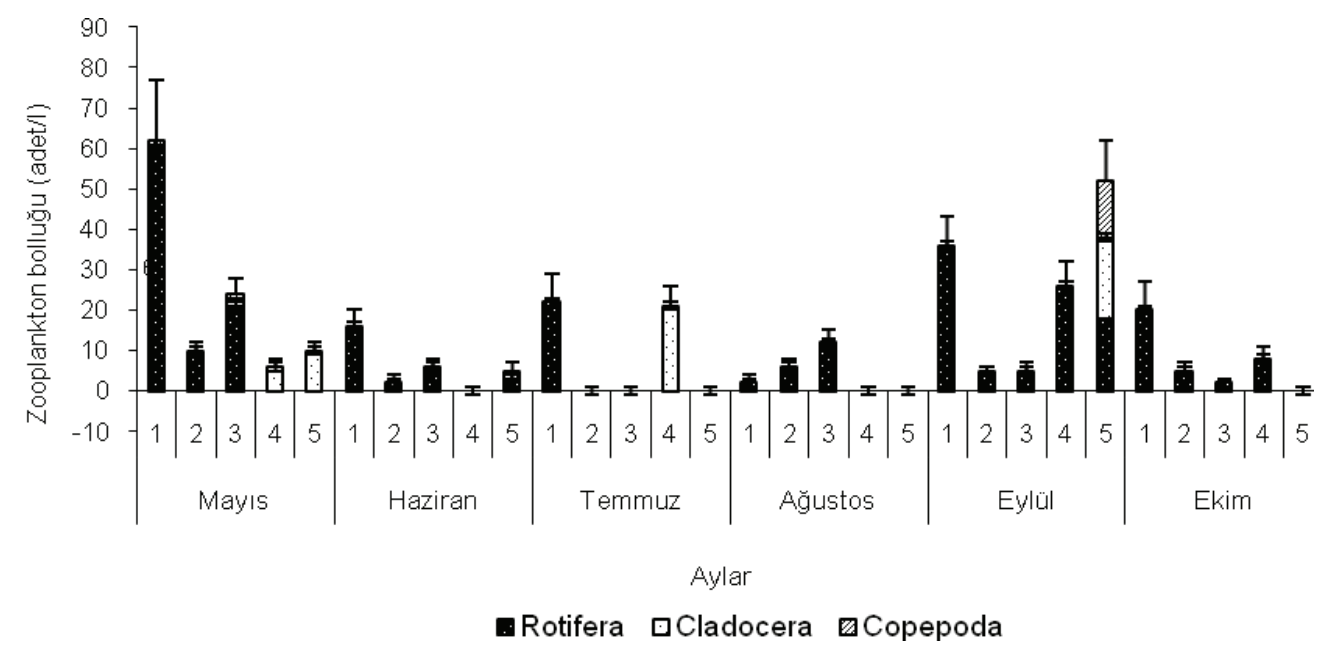

Şekil 2. Porsuk Çayı'nda örnek alınan istasyonlarda zooplankton bolluğunun aylık değişimi (ortalama zooplankton sayısı \pm standart hata) (1. istasyon-içme suyu arıtım tesisi, 2. istasyon-Kum tutucu yapı, 3. istasyon-Taşköprü, 4. istasyon-Köprübaşı, 5. istasyon-Salhane).

Porsuk Çayı'nda istasyonlarda bentik makroomurgasızlardan Hirudinea alt sınıfı Erpobdellidae familyasına ait üyeler ve Oligochaeta sınıfına ait Tubificidae familyasından Tubifex, Gastropoda sinıfı Planorbidae familyasına ait Planorbis, Physidae familyasına ait Physa, Pelecypoda sinıf Sphaeriidae familyasına ait Sphaerium cinsleri teşhis edilmiştir (Çizelge 1). Araştırma süresince, örnek alınan tüm istasyonlar dikkate alındığında sadece 4 . ve 5. istasyonlarda bentik makroomurgasızlara rastlanmıştır.

\section{Tartışma}

$\mathrm{Bu}$ araştırmada, Porsuk Çayı'nda sucul makrofitlerin ve zooplanktonun aylara ve istasyonlara bağlı değişimler gösterdiği belirlenmiştir. Porsuk Çayı'nda Chlorophyta'dan ipliksi alg Cladophora, su yüzeyinde kalın kütleler oluşturmakta ve estetik görünümü bozmaktadır. Round (1953), sularda en çok sorun yaratan alglerden birinin Cladophora olduğunu bildirmektedir. İpliksi bir yeşil alg olan Cladophora substratum üzerinde bir örtü oluşturmakta ve sudaki besin artışına paralel olarak yoğun bir gelişim göstermektedir. Bu bitkinin organik olarak kirlenmiş akarsularda bulunması, geceleri oksijenin düşmesine neden olmakta ve bu duruma koşut olarak balık ölümleri meydana gelmekte, böylece suyun dinlence amaçlı kullanımı söz konusu olmamaktadır (Mason, 1991). Porsuk Çayı'nda Spermatophyta'dan Ceratophyllum demersum, Lemna minor, Myriophyllum spicatum, Nasturtium officinale ve Potamogeton pectinatus gibi bitkiler bulunmuştur. Myriophyllum spicatum türünün ise bulanıklığı artan sularda bile yapraklarını su yüzeyine ulaştırarak 1şıtan yararlanabildiği bildirilmektedir (Cooke et al. 1993). Bu bitki yoğun Cladophora örtüsünün altında azalan 1şık koşullarında gelişebilmektedir. Phragmites australis ise daha sığ olan 1. ve 2. istasyonlarda su kıyısında kemer oluşturmaktadır. Araştırmada ekim ayı dışında 3., 4. ve 5. istasyonlarda su altı bitkilerinin bulunmadığ 1 , sadece ipliksi alglerin varlığ 1 tespit edilmiştir. Bu durum su kalitesindeki bozulmanın yanı sıra, bulanıklığın artmasından da kaynaklanmaktadır. Duarte et al. (1986), su altında 1şıklanmanın bitki biyokütlesi ve örtüsünü etkileyen en önemli faktör olduğunu bildirmişlerdir. Ayrıca Anonymous (2003)'e göre çok kirli (4. sınıf) sularda makrofitler ya azdır veya hiç bulunmamaktadır. Bu çalışma ile eşzamanlı olarak yapılan araştırmada Porsuk Çayı'nın nitrat ve amonyak derişimine bağlı olarak orta derecede kirli, nitrite göre çok kirli, ortofosfat derişimine göre ise orta derecede 
kirliden-kirliye değişim gösterdiği bildirilmiştir (Demir ve ark., 2011). Ayrıca Porsuk Çayı ve Baraj Gölü'nde yapılan daha önceki çalışmalarda, çayın çok kirli olduğu, baraj gölü’nün hiperötrofik düzeyde bulunduğu belirtilmiştir (Çiçek ve Koparal, 2001; Ocak ve ark., 2002; Yüce ve ark., 2004; Muhammetoğlu ve ark., 2005; Yüce ve ark., 2006; Bingöl ve ark., 2007).

Araştırmada zooplankton süksasyonu açısından düzenli bir değişim gözlenmemiştir. Bu durum kanallardaki suyun boşaltımı sonucu su akımındaki hızlı değişimlerden kaynaklanmaktadır. Zooplankton grupları içinde özellikle rotiferler su kalitesi açısından indikatör organizmalar olup, araştırmada teşhis edilen rotifer türleri Sladecek (1983)'e göre Porsuk Çayı'nda mesosaprobik-kirli koşulların varlığını göstermektedir. Aynı şekilde araştırmada teşhis edilen rotifer ve cladocera türlerinin bol bitkili sularda yaşadığı ve kirliliğe toleranslı olduğu Saksena (1987) tarafindan bildirilmiştir.

Porsuk Çayı üzerinde bentik makroomurgasızlar sadece 4. ve 5. istasyonlarda bulunmuştur. Bentik makroomurgasızlardan çalışmada tespit edilen sülükler (Erpobdellidae), Oligochaeta ve Gastropoda takımı makromurgasızlar organik kirliliğe karşı duyarlılıklarına göre sınıflandırıldıklarında toleranslı ve en çok toleranslı organizmalar arasında yer almaktadır (MetcalfeSmith, 1994). Bentik makroomurgasız kompozisyonu toleranslı türleri içerdiğinden araştırma bölgesi makroomurgasızlar açısından kirli sular (4. sınıf) sınıfina girmektedir (Anonymous, 2003). Bu özelliğe sahip sular, içme ve kullanma suyu olarak uygun değildir.

Sonuç olarak, Porsuk Çayı'nda, 1. ve 2. istasyonlardan itibaren yoğun kirlenme baskısı nedeniyle sucul makrofit, zooplankton ve bentik makroomurgasıların kompozisyonu önemli derecede etkilenmiş ve su kalitesindeki bozulmanın bu canlı grupları üzerine etkileri ortaya konmuştur. $\mathrm{Bu}$ bağlamda su kirlenmesinin önlenmesi sağlıklı bir ekolojik ortamın oluşması için gereklidir. Araştırma sonuçları Porsuk Çayı'nın temizlenmesi için gerekli önlemler alındığında, sucul makrofitler, zooplankton ve bentik omurgasız kompozisyonundaki değişimlerin izlenmesine temel oluşturacaktır

\section{Teşekkür}

$\mathrm{Bu}$ çalışmanın yürütülmesinde yardımlarından dolayı ESTRAM Genel Müdürü Sn. Dr. Saim Efelerli’ye, Sn. Gürler Sünel'e, ESKİ Müdürü Sn. Galip Yıldırım'a ve Sn. Hatice Çoşkun'a teşekkür ederiz.

\section{Kaynaklar}

Anonim 1998. Alıcı Ortam-Saprobik Indeksin Tayini. Türk Standartları, Ankara.

Anonymous 2003. www.epa.ie/pubs/docs/WQ.

Bingöl, A.N., Özyurt, M.S., Dayığlu, H., Yamık, A. ve Solak, C.N. 2007. Yukarı Porsuk Çayı (Kütahya) Epilitik Diyatomeleri. Ekoloji Dergisi, 15(62): 22-29.

Büyükerşen, Y. ve Efelerli, S.S. 2005. Doğal Afet Zararlarını Azaltma Yaklaşımı: Eskişehir-Porsuk Projesi. 4. Kentsel Altyapı Ulusal Sempozyumu, TMMOB İMO, 15-16 Aralik 2005.

Casper, S.J. and Krausch, H.D. 1980. Pteridophyta und Anthophyta. 1. Teil; Lycopodiaceae bis Orchidaceae, Süsswasserflora von Mitteleuropa. Band 23, Gustav Fisher Verlag, Stuttgart.

Casper, S.J. and Krausch, H.D. 1981. Pteridophyta und Anthophyta. 2. Teil; Sauruuraceae bis Asteraceae, Süsswasserflora von Mitteleuropa. Band 23, Gustav Fisher Verlag, Stuttgart.

Cooke, G.D., Welch, E.B., Peterson, A.S. and Newroth, P.R. 1993. Restoration and management of lakes and reservoirs. Lewis Publ., Boca Raton.

Çiçek, A. ve Koparal, A.S. 2001. Porsuk Baraj Gölü’nde yaşayan Cyprinus carpio ve Barbus plebejus'da kurşun, krom ve kadmiyum seviyeleri. Çevre Koruma Dergisi, 10(39): 3-6.

Demir, N., Pulatsü, S., Kirkagac, M.U., Topcu, A., Zencir, O. and Fakıglu, O. 2011. Phytoplankton composition considering the odor occurrence in the Porsuk River (Eskisehir-Turkey). Asian J. Chemistry, 23(I): 247-250. 


\section{M.U.Kırkağaç vd.}

Duarte, C.M., Kalff, J. and Peters, R.H. 1986. Patterns in biomass and cover aquatic macrophytes in lakes. Can. J. Fish. Aquat. Sci., 43: 1900-1908.

Edmondson, W.T. 1959. Freshwater Biology. $2^{\text {nd }}$ ed. John Wiley and Sons Inc. NewYork.

Edmondson, W.T. and Winberg, G.G. 1971. A Manual on Methods for the Assesment of Secondary Productivity in Freshwaters. Blackwell Sci. Publ., Oxford.

Foissner, W. and Berger, H. 1996. A user-friendly guide to the ciliates (Protozoa, Ciliophora) commonly used by hydrobiologists as bioindicators in rivers, lakes and waste waters, with notes on their ecology. Freshwater Biology, 35: $375-482$.

Hawkes, H.A. 1979. Invertebrates as Indicators of River Water Quality (In the Biological of Water Quality, Edited by A. James and L. Evision), Wiley-Interscience Publication, Great Britain.

Kayar, V.N. and Çelik, A. 2003. Gediz Nehri Kimi Kirlilik Parametrelerinin Tayini ve Su Kalitesinin Belirlenmesi. Ekoloji Çevre Derg., 12: 17-22.

Kazanc1, N. and Dügel, M. 2000. An evaluation of water quality of Yuvarlakçay Stream in the Köyceğiz-Dalyan Protected Area, SW Turkey. Turk J Zoology, 24: 69-80.

Koste, W. 1978. Rotatoria. 2 Auflage. Gebrüder Borntroeger, Berlin.

Küçük, S. 2007. Büyük Menderes Nehri su kalite ölçümlerinin su ürünleri açısından incelenmesi. ADU Ziraat Fak. Derg., 4(1-2): 7-13.

Lund, J.W.G., Kipling. C. and Le Cren, E.D. 1958. The inverted microscope method estimating algal numbers and statistical basis of estimations by counting. Hydrobiologia, 11: 143-170.

Macan, T.T. 1975. A Guide to Freshwater Invertebrate Animals. Longman, London.

Mason, C.F. 1991. Biology of Freshwater Pollution. 2nd ed. Longman Great Britain.

Metcalfe-Smith, J.L. 1994. Biological Water-Quality Assesment of Rivers: Use of Macroinvertebrate Communities. (In the Rivers Handbook, Edited by P. Calow and G. G. Petts.) Vol 2, Blackwell Science Publishing, Oxford.

Muhammetoglu, A., Muhammetoglu, H., Oktas, S., Ozgokcen, L.and Soyupak, S. 2005. Impact assessment of different management scenarios on water quality of Porsuk River and dam system-Turkey. Water Resources Management, 19:199-210.

Ocak, A., Cicek, A., Zeytinoğlu, H.ve Mercangoz, A. 2002. Porsuk Çayı suyunun bazı tarım bitkileri üzerindeki ekotoksikolojik etkileri. Çevre Koruma Dergisi, 11(45):9-13.

Prescott, G.W. 1973. Algae of Western Great Lakes Area. $5^{\text {th }}$ Ed., W. M. C. Brown Co. Publ., Dubuque.

Round, F.E., 1953. An investigation of two benthic algal communities in Malham Tarn, Yorkshire. Journal of Ecology, 41:174-197.

Ruttner-Kolisko, A. 1974. Plankton rotifers, biology and taxonomy. Die Binnengewasser Vol. XXV1/1, Supp.

Saksena, D.N. 1987. Rotifers as Indicators of Water Quality. Acta hydrochim. hydrobiol. 15: 481-485.

Sladecek, V. 1983. Rotifers as Indicators of Water Quality. Hydrobiologia 100: 169-201.

Smirnov, N.N. 1974. Fauna of USSR Crustacea. Vol: 1, No: 2, Chydoridae. IPST, Jerussalem.

Türkmen, A. ve Türkmen, M. 1999. Karasu Irmağının (Aşkale Mevkii) bazı su kalitesi parametrelerinin mevsimsel değişimi ve su ürünleri açısında değerlendirilmesi. X. Ulusal Su Ürünleri Sempozyumu, 22-24 Eylül, Adana.

Westlake, D.F. 1986. The direct determination of biomas of aquatic macrophytes and measurement of underwater light. Crown copyright., HMSO, London.

Wetzel, R.G., Likens, G.E. 1991. Limnological Analysis. $2^{\text {nd }}$ ed. Springer Verlag, New York.

Yüce, G., Arzu, P., Sakır, O. and Didem, U. 2004. The pollution of water resources in the Eskisehir region within the Porsuk River basin, Turkey. Environmental Engineering and Management Journal, 3(3): 323-343.

Yüce, G., Arzu, P., Sakır, O. and Didem, U. 2006. Soil and water pollution derived from anthropogenic activities in the Porsuk River basin, Turkey. Environmental Geology, 49:359-375 